\title{
Survey on the Global Green Computing Initiatives
}

\author{
Mariam Mesaad \\ Department of Electrical and \\ Computer Engineering \\ King Abdulaziz University, \\ Jeddah, KSA
}

\author{
Basma Saad \\ Department of Electrical and Computer \\ Engineering \\ King Abdulaziz University, Jeddah, KSA
}

\author{
Hala Alansari \\ Department of Electrical and \\ Computer Engineering \\ King Abdulaziz University, \\ Jeddah, KSA
}

\author{
Maram Ahgamdi \\ Department of Electrical and \\ Computer Engineering \\ King Abdulaziz University, \\ Jeddah, KSA
}

\author{
Hemalatha M. \\ Department of Electrical and Computer \\ Engineering, \\ King Abdulaziz University, \\ Jeddah, KSA
}

\begin{abstract}
With the widespread computing technologies, are deployed in every aspect of life including health, education, communication, transportation. In the industry, the technology evolution has been expected to affect the environment somehow, which is recently has been proved. The latest researches taken these critical environmental issues seriously to analysis and design more efficient and safe technologies to aid the planet safety. Green Computing is one of the new designed environmentally-friendly solutions which is concerned on improving the manufacturing, recycling and disposing used methods to provide more clean and healthy new generation of technologies devices. This review paper provide an analysis of the current green computing initiatives and comprehensive comparison between them in how efficient they are.
\end{abstract}

\section{Keywords}

Green Computing, Waste Management, EPA

\section{INTRODUCTION}

Green computing is a highly motivated smart computing which it introduces ways of providing technology in efficient manner with minimal impact on environment. Such that green computing saves energy to avoid power consumption where the demand for high speed internet access has increased. It aims towards electricity saving and less amount of heat generated by the computers. In the period of 1994 to 2007, there was a huge increase of the desktops sales where it reached 5.52 million [1].Widespread use of computers and related IT products has an impact on the environment. Furthermore, green computing environmental issues is also taking in consideration the end-of-life equipment which have serious impacts on human health and the environment and it has some management practices contain different means of final disposal. In the U.S. alone, the latest estimations have predicted that more than 500 million computers had become obsolete in the period from 1997 to 2007 [2]. E-waste defines as a generic term embracing all types of waste containing electrically powered components including both valuable materials as well as hazardous materials which require special handling and recycling methods. The state-of-the-art recycling technologies, which comply with high environmental and occupational health standards and hazardous technologies that prevent a great risk for both health and environment.
On the side of electromagnet pollution, green computing researches has also concerned on this kind of computing devices impact. Computer monitors generate several types of potentially hazardous radiation. The human body now experiences every day an average of EMF level approximately at 50 times greater than our parents experienced at the same age. When these radiation passes through the human body it induces electric extrinsic current beside the naturally body generated. These improper generated pulses inside the body will definitely affect the body internal physical balances.

Currently, the environmental agencies and organization are encouraging the industry to go for more clean manufacturing and efficient power consumption. Hence, many years ago, the leading companies have started competing to label their products with the environmental safety awards. These standard awards were applied to enhance the environmental health as well to aware the users of the quality and efficiency of the products.

\section{THE CURRENT MOST SUCCESSFUL GREEN COMPUTING INITIATIVES \\ 2.1 Energy Star Program}

It is a voluntary efficiency evaluation program established in 1992 by the US Environmental Protection Agency (EPA), it aims to label the most energy-efficient products as a recommended for environment safety by its own blue label (figure 1). It started with greenhouse gas emissions evaluation, and expanded to label thousands of products under over 70 categories including computers, heating and cooling equipment, offices equipment, home appliances and recently the large network equipment. Furthermore, Energy Star is certifying Homes based on its own assessment tools beside the services and recommendation for the public about the Energy Star building and plants. For the last 22 years, Energy Star has proofed its activities effectiveness by publishing that it has successfully saved 362 billion dollars on utility bills, also the greenhouse gas emission has decreased by more than 2.4 billion metric tons. In 2014, the last EPA reports has shown that Energy Star has saved 31 billion dollars on energy bills and reduced the methane emissions by a valued 7.7billion-dollar amount in 2014 alone [3]. 


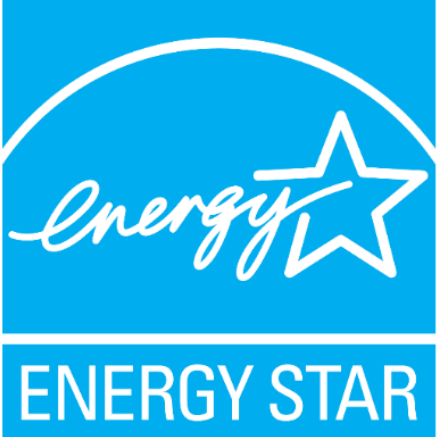

Figure 1: The Commercial widely known Energy Star Label.

\subsection{Dell's Plant a Tree Program}

Tree planting has a major to protect the environment from dangerous of pollution. So, many countries encourage to establish tree planting programmers. The most important goals of tree planting programmers are interception of storm water, carbon sequester and energy saving. Those previous goals help to avoid climate change such that environment has protected [4]. This section discusses one of the tree planting initiatives. The computers company Dell had announced for Plant a Tree Program as a part of the commitments for the American Business Act on Climate Pledge. Starting from 2008 , it aims to plant 1 million trees by 2020 . Recently customers had help planting more than 820,000 trees. The Plant a Tree program makes it easy for customers to help decrease the impact associated with electricity that power their Dell products while simultaneously helping restore habitats and protect forests. Plant a Tree Program commitment has been established with two non-profit partners, the Conservation Fund and Carbonfund.org to support this initiative. Dell also encourages their customers to pay nominal donation to plant trees that will reduce their footprint of using Dell' products and it will help them contribute to real reforestation. [5]. Furthermore, it helps to make our environment to be carbon neutral since trees will help to absorb carbon dioxide from air. Hence, this program has an effective role to provide optimal energy to the environment and keeping it safe from technology risks especially carbon dioxide gas which is achieving green computing.

\subsection{HP Planet Partners Return and \\ Recycling Program}

In 1991, HP launched the Planet Partner Return and Recycling Program and committed to help the customers recycling around the world. According to this commitment HP provides more environmentally responsible recycling solutions globally through HP Planet Partners return and recycling program. This program aims to enable simple, convenient recycling manners of HP inkjet and LaserJet supplies or any other brands' computer hardware and rechargeable batteries. Therefore, it will return and recycle plastics and metals products properly which leads to diverting millions of tons of waste from landfills. When a customer return an HP print cartridge or any brand of computing hardware for recycling each one of these return products are being processed through a multi-phase recycling process using state-of-the-art recycling facilities. Firstly, products are sorted and shredded then separated into plastics and metals. Also, the remaining ink is also separated and disposed of in an environmentally safe manner. Finally, the recovered plastic and metal materials are processed into their raw forms to be used in new HP computers, printers and other everyday products [6].

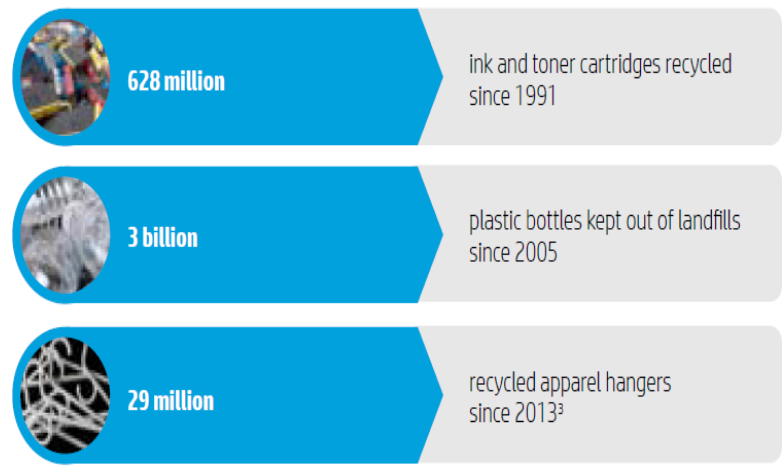

Figure 2: HP Planet Partners Return and Recycling Program achievements.

The latest statistics has proofed how effective HP Planet Partners return and recycling program is as shown in figure 2 [7]. In addition to the huge environmental benefits of waste plastics recycling there are also other characteristics of this program such as the easiest and convenient of return computing hardware process. There is no impact of this program neither on the economy nor the environment, but it can be developed in the future by increasing the proportion of environmentally friendly materials in products.

\section{ELECTRONIC PRODUCT ENVIRONMENTAL ASSESSMENT TOOL (EPEAT)}

Electronic Product Environmental Assessment Tool (EPEAT) is a free and reliable source of environmental product ratings that makes it easy to select high-performance electronics that meet an organization's IT and sustainability goals. In 2003, the system started with the convened stakeholder process by the environmental safety agency in the U.S. and it has developed to be the decisive on of electronics global environmental evaluating systems. Under the green electronic Council management, EPEAT presently tracks over 4400 products from over 60 producers through 43 countries. The environmental criteria of the EPEAT comprehensively addresses the product lifecycle, from design and manufacturing to power consumption and recycling. EPEAT products evaluation is primarily based on ANSI-authorized public requirements evolved the stakeholder agreed approaches. Producers' requests of compliance are issue to currently going verification via certified certification our bodies. Merchandise observed non-conformant are eliminated from the EPEAT registry to make certain consumers international can use the gadget with self-belief. EPEAT presently consists of product rankings for desktops and suggests (including pills), imaging machine (which incorporates printers, copiers, scanners and multi-function devices) and televisions. Environmental management necessities are currently under improvement with the motive to shape the idea of future EPEAT classes for cell telephones, servers and different digital merchandise. A non-fiduciary advisory council presents input and advice approximately EPEAT enlargement and different relevant problems. The system enables purchasers take the guesswork out of figuring out whether a tool meets their sustainability directives, and its global applicability permits large agencies to standardize procurement around a common specification. Consumers can look for electronics based on product category, manufacturer, 
geography or EPEAT rating. EPEAT-registered products can even be recognized based totally on specific attributes valued through an organization (discount of toxic substances, recyclability, use of recycled plastic, and so forth.). Producers check in merchandise in EPEAT based totally on the devices' capability to meet positive required and optionally available standards that deal with the entire product lifecycle, from design, production to electricity use, and recycling. Bronzerated products meet all of the required standards of their class. Silver-rated products meet all of the required criteria and as a minimum $50 \%$ of the optional standards, while Gold-rated merchandise meet all the required standards and at the least $75 \%$ of the optionally available standards. Manufacturers' claims of compliance are difficulty to ongoing verification with the aid of way of certified certification our bodies. Merchandise located non-conformant are announced publicly and eliminated from EPEAT to make certain purchasers global can use the tool with self-assurance. Imposing EPEAT settlement language additionally gives purchasers an automobile for requiring providers to report all EPEATregistered merchandise purchased through that agreement all through a given year. This information, if shared with the inexperienced Electronics Council, qualifies the purchaser for annual popularity and can be used to calculate the patron's precise monetary and environmental blessings [8].

EPEAT presents a benchmark with which to gage the environmental effect of a purchase which is a big benefit to manufactures because they now not need to guess what to focus on, and what sort of they ought to enhance. This software permits them to attention on specific upgrades, which assist to comprise their charges. Further, a digital tool that fulfills the necessities for EPEAT certification may also skip European requirement, thereby making it easier to export device. Consumers respect EPEAT because it gives statistics by using which they can ensure conformance with the corporation's environmental objectives. Of course, cerement buyers rely upon EPEAT certification when purchasing electronic equipment [9].

The EPEAT system encourages manufacturers to layout their products to remaining longer, include less dangerous fabric, to be more strength efficient and to be less difficult to improve and recycle. In this, it resembles numerous different labels that deal with digital merchandise. However, EPEAT's unique traits - comprehensive standards, global insurance, level of manufacturer participation, use unique element, breadth of participation and imperative net-based product registrytogether with its ongoing and transparent policing of manufacturer declarations imply that the usage of the EPEAT gadget drives those modifications more efficaciously via a broader section of the IT marketplace than using another device [10].

\section{COMPARISON ON THE ENVIRONMENTAL SUSTAINABILITY INITIATIVES}

The previously listed initiatives are the most globally running in order to achieve the environmental sustainability. The common main goal of all these initiatives and procedures is efficient utilization of environment resources. The main area of green computing researching is enclosed in: Energy Consumption, E-Waste Recycling, Data Center Consolidation \& Optimization, Virtualization and IT Products and ecolabeling [11]. Where energy is the most critical issue and it is one of the common points between the current green computing initiatives. Taking Energy Consumption in consideration, the Energy Star and EPEAT initiatives are the most successful program based on the latest energy savings statistics and their users trusted labeling. On the other hand, IT products and eco-labeling initiatives was the most effective program on the technology market. Due to the computing current revolution, the first place of the commercial products were the computers. Dell's Plant a Tree program has a direct impact on the environment. Latest researches have shown that the combination of planting trees and other vegetative covering have a significant cooling effects which reflectivity resulted of urban temperatures reduction between 1 and $7^{\circ} \mathrm{C}$. Tree planting was most successful procedure of these activities, since it had the most effective cooling achievement [12]. In addition, HP Planet Partners Return and Recycling Program has also proofed who recycling their huge number of used devices and printers have significant effect on the materials usage on manufacturing new devices which is one of the most critical green computing issues, resource utilization. On the side of E-Waste, HP program is the greenest computing waste-management successful initiatives regarding how these wastes could harm air, soil, water, animals and most importantly human's health. Consequently, the previously listed green computing initiatives are achieving the same goal by using different manners based on the diversity of the green computing definition. Therefore, each of these initiatives is participating on environmental sustainability and safety by focusing on various aspects staring from the green design and manufacturing, green using and green disposal and the most importantly the environment repayment side by increasing the green areas. The world responsibility towards the environment must be enhanced by supporting these initiatives and focusing on the nature's rights on human awareness.

\section{CONCLUSION}

The green computing initiatives are globally guiding the industry towards cleaner and safer technology revolution. Today, it can be recognized how the market's products are being eco-labeled and classified by the environment organizations which is the most important step because every practice begins with people awareness. The next portion green computing is taking care of is what is the end-of-life products by enforcing more economically saving and healthier disposal manner on the world-wide industry. Furthermore, the involved agencies and organization have controlled the production process by setting manufacturing standards that ensures the materials used are licensed. This survey has taken four of the globally green computing initiatives and showed the achieved goals of them and how they had benefited the environment. The green computing initiatives are growing and being applied in real world after the huge impact of the human activities have reached serious levels. The future of green computing is expected to be more tremendous.

\section{REFERENCES}

[1] R. K. M. Maheshwar Dwivedy, "Future trends in computer waste generation in India, " Waste Managment, vol. 30, pp. 2265-2277, 2010.

[2] Y. F. Guan, J. Z. Wang, H. G. Ni, X. J. Luo, B. X. Mai and Zeng, "Riverine Inputs of Polybrominated Diphenyl Ethers from the Pearl River Delta (China) to the Coastal Ocean," Environ. Sci. Technol, vol. 41, no. 17, p. $6007-$ 6013, 2007.

[3] "Energy Star," EPA - Energy Star, [Online]. https://www.energystar.gov/. 
[4] B. C. F. a. J. V. Sarah Widney, "Tree Mortality Undercuts Ability of Tree-Planting Programs to Provide Benefits: Results of a Three-City Study," Forests, vol. 7, no. 3, p. 65,2016

[5] "Join Dell's Plant a Tree Program: Support Reforestation," Dell, 2017. [Online]. Available: http://www.dell.com/learn/us/en/uscorp1/corpcomm/plantatreeforme.

[6] "HP Planet Partners Return and Recycling Program," HP, 2007. http://www.hp.com/hpinfo/newsroom/press_kits/ 2008/macworld/ds_hpplanetpartners_recyclingprogram.p df.

[7] "Partner with HP for the environment," HP , 3 may 2015. https://h30248.www3.hp.com/recycle/ereturns/pdfs/broc hure/planet_partners_brochure-en.pdf.
[8] "About EPEAT," Green Electronics Council , 2017. http://www.epeat.net/about-epeat/.

[9] L. W. a. M. Wallace, Green tech, New York : American Management Association,, 2009.

[10] J. Katz, "EPEAT and Promoting EPP," U.S. Environmental Protection Agency, 2014.

[11] M. S. Tariq Rahim Soomro, "Green Computing: From Current to Future Trends," World Academy of Science, Engineering and Technology, vol. 6, no. 3, 2012.

[12] S. B. V. J. a. H. D., "Managing climate change in cities: Will climate action plans work?," Landscape and Urban Planning , p. 263-271, 2012. 